\title{
EFICIÊNCIA DE UM RETARDANTE DE FOGO DE LONGA DURAÇÃO UTILIZADO EM INCÊNDIOS FLORESTAIS
}

\author{
EFFICIENCY OF A LONG TERM RETARDANT USED IN FOREST FIRE
}

\author{
Cláudio Machado Filho ${ }^{1}$ Maria Cristina Martins ${ }^{2}$ Guido Assunção Ribeiro ${ }^{3}$ Gumercindo Souza Lima ${ }^{4}$ \\ Marco Túlio Cardoso ${ }^{5}$ Carlos Moreira Miquelino Eleto Torres ${ }^{6}$ Flavia Barreto Pinto ${ }^{7}$
}

\begin{abstract}
RESUMO
O objetivo do trabalho foi avaliar a eficiência de um retardante de fogo de longa duração em relação ao volume aplicado e ao tempo de aplicação. O experimento foi realizado nas dependências do Laboratório de Incêndios Florestais e de Conservação da Natureza/UFV, com aplicação da solução retardante a 600 e $900 \mathrm{ml} / \mathrm{m}^{2}$ e avaliada sua eficiência ao longo de quatro semanas, empregando-se cinco repetições. Parcelas de 3,0 x 1,0 m foram montadas em uma rampa com $27^{\circ}$ de inclinação média, com o maior comprimento no sentido do aclive, utilizando como material combustível $1,20 \mathrm{~kg} / \mathrm{m}^{2}$ de Melinis minutiflora Beauv., distribuído uniformemente sobre a parcela. A eficiência do produto foi avaliada comparando-se as quantidades aplicadas e o tempo de aplicação utilizando-se altura das chamas, velocidade, intensidade e tempo de queima, na porção com e sem o produto. Foi determinada a umidade relativa do ar e do material combustível no momento da queima. Os resultados mostraram que o tempo de aplicação não influenciou na ação do produto e que o tempo para a linha de fogo percorrer a parte da parcela com o produto foi, em média, 7 vezes mais lento que na parte sem o produto e a intensidade cerca de 8 vezes menor, apesar de o fogo percorrer toda a área. O mesmo aconteceu com a altura das chamas que foi três vezes mais baixa que na área sem o produto.
\end{abstract}

Palavras-chave: retardante de fogo; altura das chamas; intensidade e tempo de queima.

\section{ABSTRACT}

The objective of this work was to evaluate the efficiency of fire retardant in relation to the applied volume and the application period. The experiment has been realized on the Forest Fire and Nature Conservation Laboratory of the Federal University of Viçosa (UFV), in Minas Gerais, Brazil. After the solution application of 600 and $900 \mathrm{ml} / \mathrm{m}^{2}$ on five repetitions, the efficiency has been evaluated during four weeks. Parcels of 3,0 $\mathrm{X} 1,0 \mathrm{~m}$ have been built in a ramp with mean inclination of $27^{\circ}$. It has been spread $1,20 \mathrm{~kg} / \mathrm{m}^{2}$ of Melinis minutiflora Beauv as burning fuel on the area. The product efficiency has been evaluated comparing the applied quantities and the application period observing the flames height, cover speed, burn intensity and burn period on the portions with and without the product. The relative air moisture and the fuel material moisture at the burn moment have been determined. The results have shown that the application period did not have influence on the product action. The mean period that the fire line took to cover the parcel with

1. Engenheiro Florestal, Universidade Federal de Viçosa, CEP 36570-000, Viçosa (MG). claudiomf2000@yahoo.com.br

2. Turismóloga, Mestre em Ciência Florestal, Universidade Federal de Viçosa, CEP 36570-000, Viçosa (MG). leteminas@hotmail.com

3. Engenheiro Florestal, Dr., Professor do Departamento de Engenharia Florestal, Universidade Federal de Viçosa, CEP 36570-000, Viçosa (MG). gribeiro@ufv.br

4. Engenheiro Florestal, Dr., Professor do Departamento de Engenharia Florestal, Universidade Federal de Viçosa, CEP 36570-000, Viçosa (MG). gslima@ufv.br

5. Engenheiro Florestal, Doutorando em Ciência Florestal, Universidade Federal de Viçosa, CEP 36570-000, Viçosa (MG). mtulio_cardoso@yahoo.com.br

6. Engenheiro Florestal, Mestrando em Ciência Florestal, Universidade Federal de Viçosa, CEP 36570-000, Viçosa (MG). carlos.eleto@yahoo.com.br

7. Engenheira Florestal, Pós-graduação Plantas Ornamentais e Paisagismo, Universidade Federal de Viçosa, CEP 36570-000, Viçosa (MG). flaviabarto_ufv@yahoo.com.br

Recebido para publicação em 12/03/2009 e aceito em 18/05/2011 
the product was, in average, seven times slower than the part without the product. The burn intensity was around eight times minor, despite the fire covered all area. The same occurred to the flames height which was three times lower than the area without the product.

Keywords: fire suppressant; flames height; burn intensity and burn period.

\section{INTRODUÇÃO}

A importância do fogo para a humanidade pode ser vista pela ótica do homem das cavernas o qual não possuía qualquer forma de obter a luz. Com o domínio do fogo, o homem percebeu que ele podia ser "cultivado". A partir daí a vida em sociedade começou a se desenvolver; as pessoas passaram a se reunir em volta de fogueiras, surgindo as primeiras tribos. Unidos para se aquecer eles passaram a se comunicar mais, dando origem às formas mais elaboradas de comunicação, como a fala e as escritas rupestres (MARTINS et al., 2007).

O fogo foi e é um importante instrumento de trabalho, ainda tem um importante papel na evolução da humanidade, continua sendo utilizado pela indústria, e principalmente, pelos produtores rurais na limpeza de suas áreas. O maior problema ocorre quando esta prática foge do controle, causando acidentes e destruição.

O comportamento do fogo durante um incêndio depende de fatores que interagem entre si a cada momento, fazendo com que a linha de fogo evolua e se renove. O material combustível, ao ser consumido, gera energia fazendo com que o fogo se desloque para novos espaços, dando continuidade ao processo da combustão, enquanto as condições do ambiente facilitarem a reação da combustão.

Um dos fatores que influenciam na combustão é o material combustível que é a matéria que irá queimar durante o incêndio. Cada material tem um poder calorífico, forma e tamanho que irá influenciar na intensidade do fogo. O seu teor de umidade também é um fator que influencia na combustão, uma vez que parte da energia do incêndio será gasta na evaporação desta água.

A topografia também auxilia no comportamento, pois dependendo da declividade a linha de fogo irá se propagar com mais velocidade. Quando o fogo está seguindo no sentido do aclive a tendência é da velocidade ser maior, já que as chamas ficam mais próximas da parte do terreno ainda não queimadas, assim pré-aquecem com mais eficiência o material combustível, facilitando a pirólise.

O tempo de duração é outro fator que influencia o espalhamento do fogo, uma vez que o incêndio ganha mais força à medida que ele aumenta de dimensão e os fatores meteorológicos, principalmente as variáveis relacionadas com a umidade, são os determinantes nas ocorrências dos grandes incêndios florestais. Por outro lado, o fogo não se inicia sem uma fonte inicial de energia. Esta fonte pode ocorrer de forma natural, como em uma descarga elétrica ou de forma criminosa, praticada pelo ser humano. Este último é o responsável pela maioria dos incêndios nas áreas rurais.

Segundo Pardo (2007), os retardantes de longa duração são sais compostos basicamente por polifosfato de amônia, que são diluídos em água para aplicação. São aplicados sobre o material combustível para retardar a combustão e esta ação continua mesmo após a evaporação da água. A ação do produto é impedir que ocorra a pirólise, transformando-o em uma substância não inflamável. A ação do produto permanece até com precipitações máximas de $4 \mathrm{~mm}$ de chuva. Nessas condições, o produto se manterá com todas as características retardantes por tempo indeterminado.

$\mathrm{O}$ produto pode ser aplicado facilmente com a ajuda de bombas costais anti-incêndio em pequenas áreas. E em áreas maiores com o auxílio de máquinas agrícolas ou ainda pelo ar, com aviões ou helicópteros.

No Brasil, os retardantes de fogo são muito pouco conhecidos e por isto são pouco utilizados. Um fator que realça esta não utilização são os elevados preços dos mesmos, já que o produto não é fabricado no país.

O produto utilizado no estudo foi o phoschek. É um retardante de longa duração, tendo como princípio ativo uma mistura de fosfato de amônio e sulfato de amônio. O produto retardante altera a flamabilidade do material combustível, desviando o sentido da reação da combustão, quando exposto ao fogo. $\mathrm{Na}$ presença do retardante, a liberação dos gases inflamáveis, os quais contribuem com o pré-aquecimento, combustão em chamas e o consequente espalhamento do fogo, não ocorre, pois, na presença do produto retardante o material em combustão é transformado diretamente para carvão com liberação de água. A água, ao evaporar, 
absorve calor, resfriando o combustível e, consequentemente, dificultando a continuação da reação da combustão por causa da barreira formada (RIBEIRO et al., 2006).

O objetivo deste trabalho foi avaliar a eficiência de duas dosagens do retardante de fogo de longa duração no decorrer de quatro semanas, visando a sua utilização na prevenção contra incêndios florestais.

\section{MATERIAL E MÉTODO}

O trabalho foi realizado nas dependências do Laboratório de Incêndios Florestais e de Conservação da Natureza, do Departamento de Engenharia Florestal, da Universidade Federal de Viçosa. As parcelas com dimensão de 3,0 x $1,0 \mathrm{~m}$ foram demarcadas em uma rampa com declividade média de $27^{\circ}$, direcionando seu maior comprimento no sentido do aclive. Para manter o controle da mesma quantidade de material combustível nos tratamentos e repetições, retirouse toda matéria orgânica das parcelas demarcadas por meio de capina manual, e espalhou-se 3,60 kg de capim gordura (Mellinis minutiflira) seco, de maneira a formar uma manta uniforme de $1,20 \mathrm{~kg}$ de combustível por metro quadrado.

Foram montadas 48 parcelas, sendo 20 para cada tratamento e 8 para controle. Os tratamentos consistiram de duas dosagens do produto comercial, composto de fosfato de amônio com sulfato de amônio, sendo aplicados $600 \mathrm{ml} / \mathrm{m}^{2}$ e $900 \mathrm{ml} / \mathrm{m}^{2}$, formando a calda retardante de fogo. Conforme recomendação do fabricante, a calda é formada na base de $134 \mathrm{~g}$ do produto por litro de água.

O volume de cada tratamento $(600$ ou $900 \mathrm{ml} / \mathrm{m}^{2}$ ) foi aplicado somente no terço superior da parcela, que tinha sido previamente sorteada para todo o experimento, utilizandose de uma bomba costal anti-incêndio, em seu estágio mais pulverizado. Procurou-se fazer uma pulverização uniforme sobre a superfície da subparcela de $1 \mathrm{~m}^{2}$.

A queima era iniciada na parte inferior da parcela para que a linha de fogo atingisse a porção com o retardante já plenamente estabelecida. As queimas foram feitas semanalmente, iniciando-se uma semana após a aplicação do produto, durante quatro semanas. Em cada semana queimavam-se 5 parcelas/repetições de cada tratamento. Antes da realização da queima, media-se a umidade relativa do ar; a espessura da manta de combustível na parte central de cada subparcela (para cálculo da densidade); coletava-se material para determinação da umidade e demarcava-se a parcela de 3,0 x 1,0 m em três subparcelas de 1,0 x 1,0 m, com cordão, para facilitar as medições de velocidade de queima e altura da chama.

Após a coleta dos dados foram feitos os cálculos da umidade do material e da intensidade de queima em cada terço das parcelas, com as seguintes fórmulas:

\section{Umidade do material combustível (U)}

$\mathrm{U}=($ Peso úmido - Peso de matéria seca $) /$

Peso de matéria seca $* 100$

$$
\begin{aligned}
& \text { Intensidade do Fogo, em Kcal }{ }^{*} \mathbf{s}^{-1 *} \mathbf{m}^{-1} \text { (I) } \\
& \qquad \mathrm{I}=\mathrm{H}_{\text {úmido }} *_{\mathrm{w}} * \mathrm{r}
\end{aligned}
$$

$$
\begin{aligned}
& \text { Calor de combustão do material combustível } \\
& \text { úmido em Kcal } \mathbf{K g}^{-1}\left(\mathbf{H}_{\text {úmido }}\right) \\
& \qquad \mathrm{H}_{\text {úmido }}=\mathrm{H}_{\text {seco }} *[(100-\mathrm{U} / 7) / 100+\mathrm{U}]
\end{aligned}
$$

Peso do material combustível seco consumido, em $\mathrm{kg}^{*} \mathbf{m}^{-2}(\mathrm{w})$

$\mathrm{W}=[$ peso do material combustível antes da queima $\left.\left(1,20 \mathrm{~kg} / \mathrm{m}^{2}\right) /(100+\mathrm{U})\right]^{*} 100$

\section{Velocidade da linha de fogo, em $\mathrm{m}^{*} \mathrm{~s}^{-1}(R)$}

$\mathrm{R}=$ metro/tempo em segundos

Após o cálculo das variáveis foram determinadas as médias e os desvios padrões de cada uma, para se ter a confiabilidade da média. Levando em consideração a variação da intensidade da queima nos diferentes trechos e no decorrer de todo o período da experimentação, foi feito o teste t de Tukey, para se conhecer a relação que o tempo de exposição teve sobre a eficiência do retardante de fogo, e da ação do produto em relação à área das parcelas sem a aplicação do mesmo.

\section{RESULTADOS E DISCUSSÕES}

Observando os dados relacionados com a densidade (Tabela 1), pode-se notar que, nos dois tratamentos, os valores se mantiveram constantes; as suas médias foram estatisticamente iguais em todos os trechos e tratamentos a cada semana, não interferindo assim na intensidade da linha de fogo.

Se a densidade tivesse sido menor em algum dos trechos, o que implicaria em 
TABELA 1: Valores das variáveis medidas durante o tratamento de queima.

TABLE 1: Value of the variables measures during burning treatment.

\begin{tabular}{|c|c|c|c|c|c|c|}
\hline $\begin{array}{l}\text { Semana }(\mathrm{S}) \text { - } \\
\text {-Dosagem- } \\
\text {-Trecho }(\mathrm{T})\end{array}$ & $\begin{array}{l}\text { Altura da chama } \\
\text { (m) }\end{array}$ & $\mathrm{S}$ & $\begin{array}{l}\text { Intensidade } \\
\left(\mathrm{kcal} \cdot \mathrm{m}^{-1} \cdot \mathrm{s}^{-1}\right)\end{array}$ & S & $\begin{array}{c}\text { Densidade } \\
\left(\mathrm{kg} \cdot \mathrm{m}^{-3}\right)\end{array}$ & S \\
\hline S1-600-T1 & $0,7850 \mathrm{a}$ & 0,106 & $78,1304 \mathrm{a}$ & 10,130 & $0,1530 \mathrm{a}$ & 0,023 \\
\hline S1-600-T2 & $0,8138 \mathrm{a}$ & 0,202 & $79,9032 \mathrm{a}$ & 7,980 & $0,1364 \mathrm{a}$ & 0,020 \\
\hline S1-600-T3 & $\begin{array}{l}0,3246 b \\
(p=0,00122)\end{array}$ & 0,199 & $\begin{array}{l}10,9160 b \\
(p=<0,00001)\end{array}$ & 0,949 & $\begin{array}{l}0,1418 \mathrm{a} \\
(p=0,53013)\end{array}$ & 0,026 \\
\hline S2-600-T1 & $0,9540 \mathrm{a}$ & 0,280 & $76,7546 \mathrm{a}$ & 20,282 & $0,1408 \mathrm{a}$ & 0,038 \\
\hline $\mathrm{S} 2-600-\mathrm{T} 2$ & $1,1300 \mathrm{a}$ & 0,328 & $79,6176 \mathrm{a}$ & 24,573 & 0,1538 a & 0,051 \\
\hline $\mathrm{S} 2-600-\mathrm{T} 3$ & $\begin{array}{l}0,2360 b \\
(p=0,00037)\end{array}$ & 0,138 & $\begin{array}{l}8,9588 \mathrm{~b} \\
(\mathrm{p}=0,00007)\end{array}$ & 3,297 & $\begin{array}{l}0,1300 \mathrm{a} \\
(\mathrm{p}=0,65460)\end{array}$ & 0,029 \\
\hline S3-600-T1 & $0,9125 \mathrm{a}$ & 0,212 & $58,5750 \mathrm{a}$ & 4,212 & $0,14775 \mathrm{a}$ & 0,035 \\
\hline S3-600-T2 & $0,6683 \mathrm{a}$ & 0,158 & $58,0265 \mathrm{ab}$ & 28,729 & $0,15025 \mathrm{a}$ & 0,021 \\
\hline S3-600-T3 & $\begin{array}{l}0,3250 \mathrm{~b} \\
(p=0,00582)\end{array}$ & 0,197 & $\begin{array}{l}9,0960 \mathrm{~b} \\
(p=0,01074)\end{array}$ & 0,730 & $\begin{array}{l}0,1375 \mathrm{a} \\
(p=0,79542)\end{array}$ & 0,026 \\
\hline S4-600-T1 & $1,1190 \mathrm{a}$ & 0,157 & $71,5738 \mathrm{a}$ & 9,559 & $0,14925 \mathrm{a}$ & 0,029 \\
\hline $\mathrm{S} 4-600-\mathrm{T} 2$ & $1,1045 \mathrm{a}$ & 0,039 & $75,3088 \mathrm{a}$ & 15,393 & $0,14675 \mathrm{a}$ & 0,026 \\
\hline S4-600-T3 & $\begin{array}{l}0,2825 \mathrm{~b} \\
(\mathrm{p}=, 0,00001)\end{array}$ & 0,087 & $\begin{array}{l}11,3575 \mathrm{~b} \\
(\mathrm{p}=0,00002)\end{array}$ & 0,488 & $\begin{array}{l}0,15625 \mathrm{a} \\
(\mathrm{p}=0,88191)\end{array}$ & 0,028 \\
\hline S1-900-T1 & $0,9820 \mathrm{a}$ & 0,223 & $92,5590 \mathrm{a}$ & 27,613 & $0,1294 \mathrm{a}$ & 0,022 \\
\hline $\mathrm{S} 1-900-\mathrm{T} 2$ & $1,3950 \mathrm{a}$ & 0,302 & $119,1204 \mathrm{a}$ & 27,142 & $0,1298 \mathrm{a}$ & 0,025 \\
\hline S1-900-T3 & $\begin{array}{l}0,3990 \mathrm{~b} \\
(p=0,00001)\end{array}$ & 0,108 & $\begin{array}{l}15,9908 \mathrm{~b} \\
(p=0,00002)\end{array}$ & 4,595 & $\begin{array}{l}0,1294 \mathrm{a} \\
(p=0,99942)\end{array}$ & 0,017 \\
\hline $\mathrm{S} 2-900-\mathrm{T} 1$ & $1,2400 \mathrm{a}$ & 0,207 & $137,0854 \mathrm{a}$ & 39,282 & $0,1294 \mathrm{a}$ & 0,022 \\
\hline $\mathrm{S} 2-900-\mathrm{T} 2$ & $1,2320 \mathrm{a}$ & 0,295 & $85,7802 \mathrm{a}$ & 14,456 & 0,1298 a & 0,025 \\
\hline S2-900-T3 & $\begin{array}{l}0,2840 b \\
(p=0,00001)\end{array}$ & 0,053 & $\begin{array}{l}17,1664 b \\
(p=0,00002)\end{array}$ & 4,523 & $\begin{array}{l}0,1294 \mathrm{a} \\
(\mathrm{p}=0,99942)\end{array}$ & 0,017 \\
\hline
\end{tabular}

Em que: S1, S2, S3, S4 = semana um, dois, três e quatro, respectivamente. Letras iguais na mesma semana e dosagem correspondem a médias estatisticamente iguais

maior disponibilidade de oxigênio, poderia ter facilitado a combustão, aumentado a intensidade do fogo (Figura 1). O acompanhamento da densidade, ao logo do tempo, foi essencial para monitorar o nível de compactação da manta a ser queimada. Pelos resultados, esse efeito não foi observado.

Para o tratamento de $600 \mathrm{ml}$ obtiveram-se os seguintes resultados: na primeira, segunda, terceira e quarta semanas não houve diferença na altura da chama para os trechos um e dois. O trecho três foi estatisticamente diferente dos demais, obtendo-se chamas menores (Figura 2).

Para intensidade na primeira, segunda e quarta semana obteve-se o seguinte resultado: os trechos um e dois são iguais, e o trecho três é estatisticamente diferente dos demais, com intensidade menor. Na semana três observou-se uma diferença nos resultados onde o trecho dois é estatisticamente igual aos trechos um e três, porém o trecho três é estatisticamente diferente do trecho um, para intensidade (Figura 3). Esses resultados mostram claramente a influência do retardante de fogo, ou seja, o produto reduziu a intensidade de queima de forma significativa, comparando-se com a intensidade de queima dos locais onde não se aplicou o produto.

Para o tratamento com $900 \mathrm{ml}$ foram feitas apenas duas queimas, pois com o início das chuvas o experimento ficou prejudicado, uma vez que as 
parcelas se encontravam em ambiente aberto. Neste caso a densidade também foi estatisticamente igual para todos os trechos e semanas.

Para altura das chamas, as médias dos trechos um e dois foram estatisticamente iguais, enquanto que o trecho três foi diferente e estatisticamente inferior (Figura 2).

A intensidade da linha de fogo mostrou resultados dentro do esperado uma vez que o que se deseja de um retardante é diminuir a intensidade de queima. Os trechos um e dois foram estatisticamente iguais e ambos diferentes do terceiro trecho. Os valores absolutos foram visualmente diferentes, mostrando ação marcante do produto no avanço do fogo (Figura 3).

Como em todos os casos, os trechos um e dois foram estatisticamente iguais para altura da chama e intensidade da linha de fogo, as análises foram feitas comparando-se o trecho dois com o trecho três. Em ambos os casos o fogo já chega com certa força, assim pode-se comparar melhor o efeito do retardante.

Após a análise dos dados, foi feita uma análise gráfica (Figura 4) do percentual de redução da intensidade da queima e da altura da chama no trecho três, para se obter informações sobre a diferença na eficiência do retardante no decorrer do tempo.

\section{Densidade}

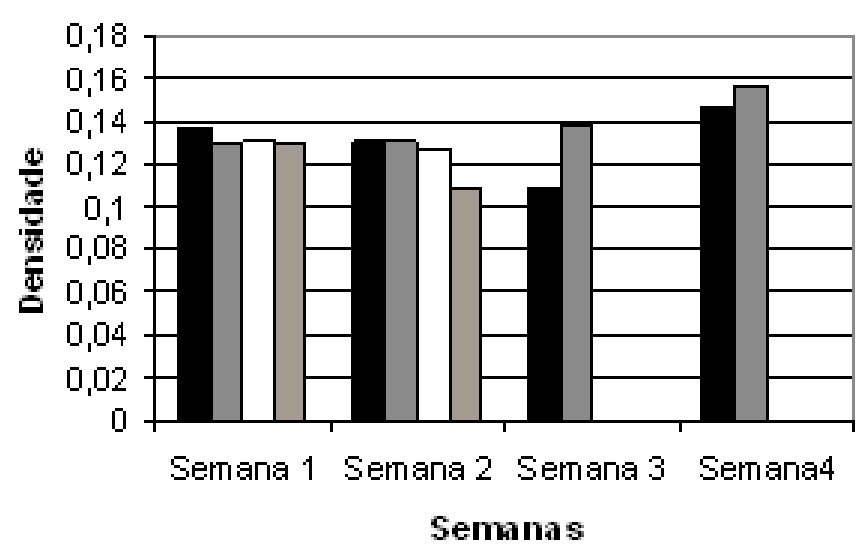

- Sern produto 600 口Com produto 600 口Sem produto 900 $\square$ Corn produto 900

FIGURA 1: Densidade dos trechos nas parcelas

FIGURE 1: Density of the sections in the plots

\section{Altura de chama}

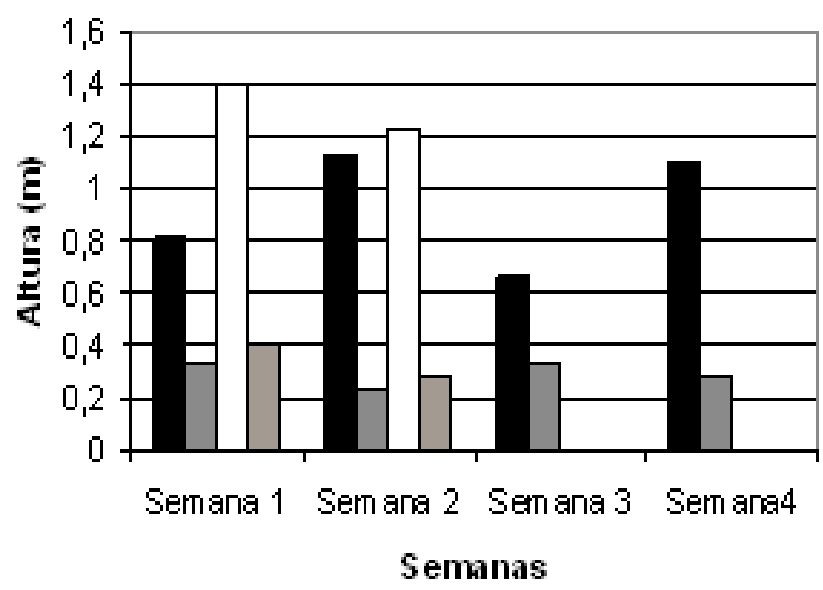

FIGURA 2: Variação na altura da chama.

FIGURE 2: Variation in height of the flame. 


\section{Intesidade de queima}

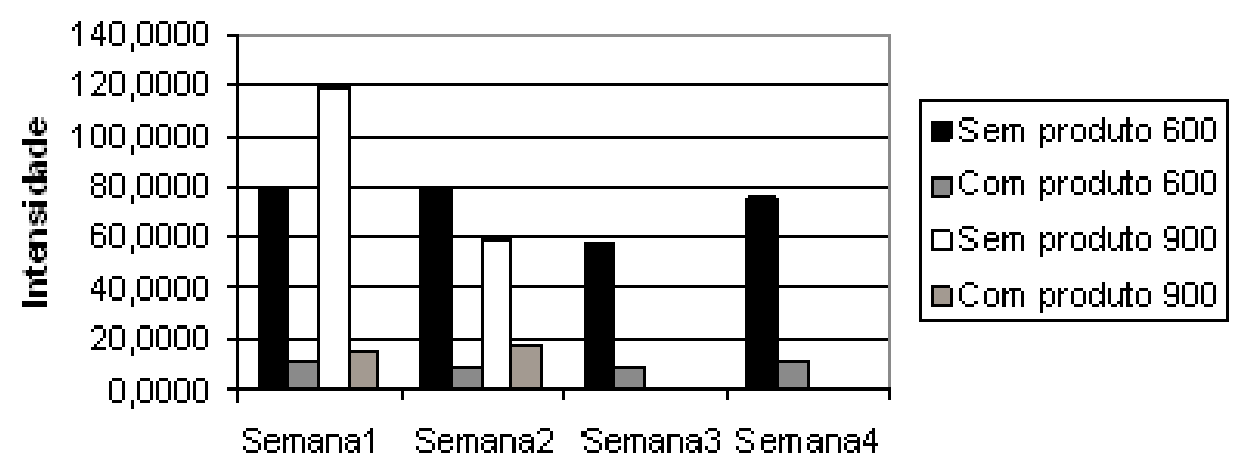

\section{Semanas}

FIGURA 3: Variação na intensidade do fogo.

FIGURE 3: Variation in fire intensity.

\section{Efeito do retardante}
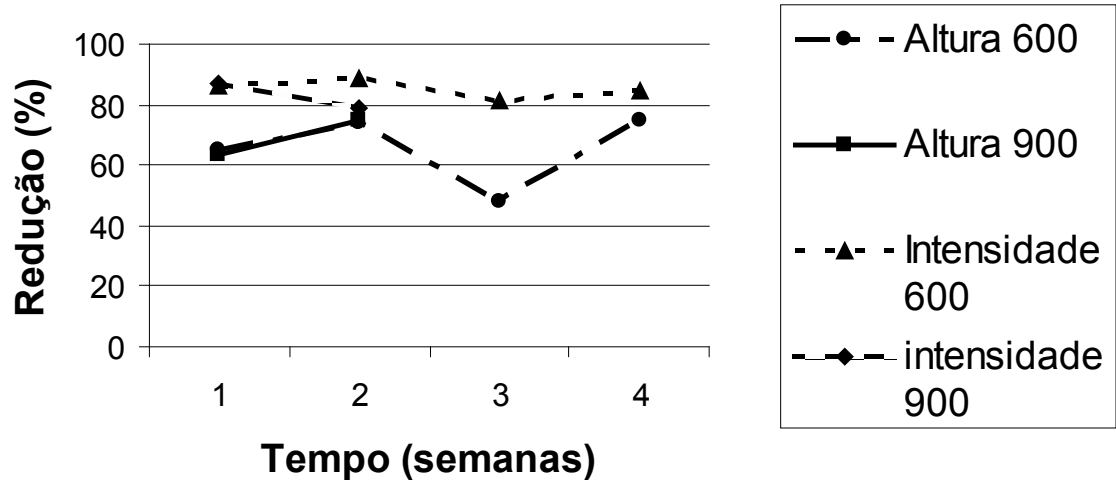

FIGURA 4: Efeito do retardante de fogo.

FIGURE 4: Effect of fire retardant.

No percentual de redução obtiveram-se os melhores resultados da intensidade na semana dois, com redução de $88,25 \%$ e de $74,48 \%$ na altura da chama na semana quatro, isto com a aplicação de $600 \mathrm{ml}$ de calda.

$\mathrm{Na}$ aplicação de $900 \mathrm{ml}$ de calda os melhores resultados foram de $86,69 \%$ de redução da intensidade na semana um e de $74,69 \%$ na altura da chama na semana dois.

\section{CONCLUSÃO}

Com base nos dados avaliados podese concluir que, o período de quatro semanas de exposição do produto às intempéries climáticas (sem a ocorrência de precipitação) não interferiu de maneira significativa na eficiência do produto. Quando avaliado o gráfico do percentual de redução, não foi observada nenhuma tendência no mesmo.

A eficiência do retardante também foi comprovada em todos os casos, e o seu efeito foi bem evidenciado, auxiliando de maneira satisfatória na redução da altura da chama e na intensidade da linha de fogo.

\section{REFERÊNCIAS BIBLIOGRÁFICAS}

MARTINS, M. C. et al. A história e a cultura do fogo. IV Simpósio Sul Americano sobre prevenção e combate a incêndios florestais e $8^{\text {a }}$ Reunião técnica conjunta SIF/FUPEF/IPEF 
sobre controle de incêndios florestais. Belo Horizonte, 2007.

PARDO, J. M. Retardantes terrestres, uma novidad en La lucha de incêndios forestales. IV Simpósio Sul Americano sobre prevenção e combate a incêndios florestais e $8^{\text {a }}$ Reunião técnica conjunta
SIF/FUPEF/IPEF sobre controle de incêndios florestais. Belo Horizonte, 2007.

RIBEIRO, G. A. et al. Eficiência de um retardante de longa duração na redução da propagação do fogo. Revista Árvore, Viçosa, Minas Gerais, v. 30, n. 6, p. 1025-1031, nov./dez. 2006. 